\title{
Supracricoid Laryngectomy
}

National Cancer Institute

\section{Source}

National Cancer Institute. Supracricoid Laryngectomy. NCI Thesaurus. Code C91839.

A conservation laryngeal surgery involving the resection of the true and false vocal cords, both parag lottic spaces, and the thyroid cartilage. In some cases the preepiglottic space and the epiglottis are also removed. 